\title{
The African Storybook and Storybooks Canada: Digital Stories for Linguistically Diverse Children
}

\author{
ESPEN STRANGER-JOHANNESSEN \\ Inland Norway University of Applied Sciences
}

\author{
LIAM DOHERTY \\ University of British Columbia \\ BONNY NORTON \\ University of British Columbia
}

\begin{abstract}
Storybooks Canada (storybookscanada.ca) makes multilingual audiovisual stories available in multiple languages to promote language and literacy development. Building on a long tradition of freely available, open educational resources, Storybooks Canada provides online, multimodal, mobile- and teacher-friendly access to 40 African stories in 21 of the most commonly spoken languages in Canada (including English and French) making it possible to support and encourage the multilingualism of heritage language, immigrant, and refugee students. In doing so, the project demonstrates the potential for working against the normalized North-South directionality of knowledge flows to develop a more equitable ecosystem for the mobilization of knowledge.
\end{abstract}

Keywords

African storybook, biliteracy, digital inequality, digital stories, heritage language learners, multilingualism, open educational resources

\section{Equity in Digital Literacy}

The increased interconnectivity of the digital age has changed the nature of social interaction, work, and learning, within and across national borders. For many, this change has led to greater opportunities for access to information, knowledge, and social networks. However, not everyone is benefitting to the same extent from the changes that are taking place. What is sometimes called the digital divide indexes the difference between those who have regular access to digital technology and those who have limited access, creating inequities amongst people and nations and exacerbating existing fault lines associated with wealth, ethnicity, and language (Warschauer, 2003, 2012; Warschauer \& Matuchniak, 2010).

Equity in digital literacy is sometimes construed as access to digital equipment, particularly Internet-enabled devices such as computers, tablets, and smartphones. There is, however, a distinct lack of digital resources for primary education in many (or, more likely, most) of the world's languages; thus, even in cases where access to the Internet is prevalent or at least available in the classroom, it is likely that there will be no resources in the home languages of all or at least some of the students in that class. This is particularly notable in Africa, where there is a significant lack of print and digital content in many of 
the more than 2000 languages spoken on the continent, as well as in North America, where although wide variety of home (or heritage) languages are spoken, educational materials are generally only available in the dominant societal language (usually English, French, or Spanish, depending on region).

The importance of language in digital equity is not restricted to developing nations. In Canada-where over 20 percent of the population speaks a language other than the official languages of English or French at home (Statistics Canada, 2012)_language should be an integral part of any debate on digital equity. When students' home languages and multilingualism are not valued, supported, and maintained, it frequently results in negative effects on their cognitive development and academic achievement (Cummins, Mirza, \& Stille, 2012). While some students who speak a non-societally dominant language at home do well in school (specifically those for whom multilingualism is supported and encouraged), other groups of students (particularly those whose other languages receive inadequate support or are considered deficits or liabilities) perform below average. This latter group typically includes students from refugee or low socio-economic backgrounds (Cummins et al., 2012; Gunderson, D’Silva, \& Odo, 2014). Extensive research has shown the academic benefits such students get from developing their first language literacy alongside the learning of English (Cummins, 2000; García \& Kleifgen, 2010; Oakes, Lipton, Anderson, \& Stillman, 2015). But equally important is the need to acknowledge students' first languages as valuable and legitimate within the school and society in general, and as sources of identity and connection to extended family and cultural ties (Cummins \& Early, 2011; Taylor, Bernhard, Garg, \& Cummins, 2008).

There is a tendency to consider attention to students' first language as the responsibility of the parents. Some parents actively support their children's first language development by sending them to study at community language schools (Baker, 2011; Creese \& Blackledge, 2010; Peterson \& Heywood, 2007). However, not all languages have community schools, and some parents might not have sufficient social, cultural, and economic capital to encourage and enable this practice. Leaving the responsibility of first language maintenance to parents therefore reinforces differences between well-resourced and poorly-resourced families, further exacerbating inequities between students (Laureau, 2011). The contribution that teachers and schools can make to reduce these inequities is significant (Cummins, 2011).

As we discuss in this article, digital affordances can be leveraged to support and develop minority languages and multilingual literacy in new ways-first and foremost by providing a commonly-accessible platform of multilingual resources for use in classrooms and at home. While print materials in minority languages may sometimes be available, the digital is extremely effective when issues of distribution, licensing, and mobile access are taken into consideration, since openly licensed materials in multiple languages can be copied, translated, and shared freely at virtually no cost (Piper, Zuilkowski, \& Ong'ele 2016). For teachers of Canadian students who speak a language other than English or French at home, this means that it is increasingly feasible to include multilingual digital resources in the school curriculum. Providing teachers with an easy-to-use, accessible, mobile-friendly, multimodal collection of such resources is the goal of Storybooks Canada (see Figure 1). 


\section{Storybooks Canada}

Storybooks Canada is designed specifically for teachers, parents, and community members. It makes 40 stories from the African Storybook available with text and audio in English and French, as well as the most widely spoken immigrant and refugee languages of Canada. We also celebrate Indigenous languages and are developing Indigenous Storybooks Canada. Share and enjoy!

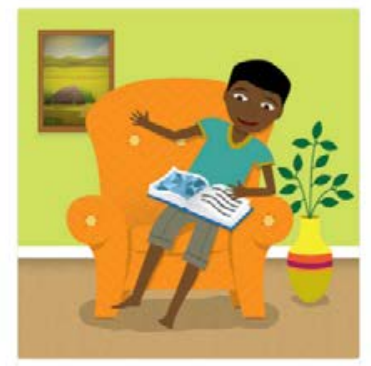

I like to read! Level1

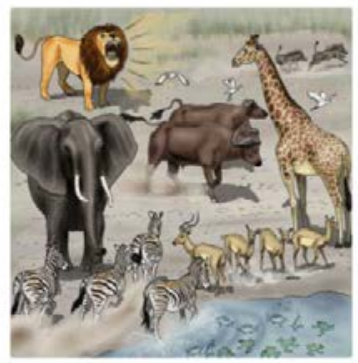

Counting animals

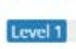

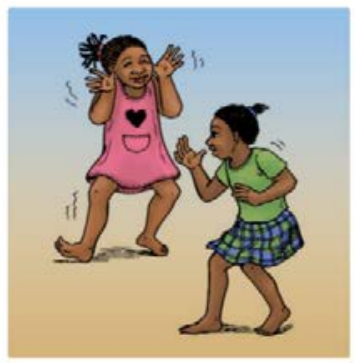

Feelings

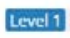

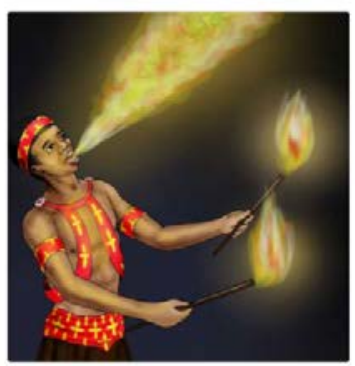

Fire



Figure 1. The Storybooks Canada website

Open Educational Resources, African Storybook, and Global ASP

The genesis of Storybooks Canada is inextricably intertwined with that of the African Storybook initiative (ASb, africanstorybook.org), which digitizes and makes hundreds of stories freely available in dozens of different African languages; the Global African Storybook Project (Global ASP, global-asp.github.io), which seeks to build upon the work done by the ASb in non-African languages; and the ecosystem of Open Educational Resources (OER), which has both sustained and made all of these projects possible. The ASb has over 800 openly licenced stories in more than 120 African languages_-as well as in English, French and Portuguese-with almost 4,000 translated stories. It was developed by the South African organization Saide, which develops OER and distance education projects. The ASb is funded by Comic Relief, a major charity in the United Kingdom.

Two authors of this article, Espen Stranger-Johannessen and Bonny Norton, are also members of the ASb team, and have researched teachers' use of these stories in a Ugandan primary school, where teachers were given a laptop and projector by Saide so that they could teach ASb stories in their classrooms (Stranger-Johannessen, 2017a; Stranger-Johannessen \& Norton, 2017). The experience of these teachers was overall very positive as they navigated previously unfamiliar technology and developed ways of integrating stories with curricular content. The most notable example was the use a story about an African girl who was not allowed to play football until one of the male players was sick and the team needed her to play (www.africanstorybook.org/index.php?id=5283). Talking about her experience with teaching this story, the teacher shares: 
Yes, it really helped me. It changed the attitudes of boys. Where they could think that a girl is not supposed to play football. But this time when I go for my physical education lesson, when I prepare a lesson about football, they don't now complain, they don't kick the ball away from the girls. They just play together like that. This time they have started attitude change instead. It helped me a lot (StrangerJohannessen \& Norton, 2017, p. 51).

Access to the ASb stories online facilitated not just an enriched literacy environment, but also new discussions and opportunities for teachers to re-negotiate their identities as change agents. In this story about the football player, the teacher turned the story into a conversation about gender roles, and in the process took on the identity of an agent of social change in her community.

As with many other digital literacy initiatives (e.g., Pratham Books, Nal'ibali, Book Dash, Little Zebra Books, Seed Books, or READ Educational Trust), the ASb is centrally concerned with equity and the creation of OER. In particular, the ASb addresses the dire lack of children's storybooks in Africa, especially in African languages. While the website that Saide has developed provides beautifully illustrated, openly licensed children's stories, users are also invited to write new stories and translate existing ones-thereby expanding the number of stories and languages available to African children.

Education in students' mother tongues is widely supported by research (Laguarda \& Woodward, 2013; Ouane \& Glanz, 2010; Piper et al., 2016; Trudell, 2013), but in practice, African teachers often resort to teaching in the dominant colonial languages (English, French, and Portuguese), partly because of the lack of materials in local languages (Babaci-Wilhite, 2010; Ouane \& Glanz, 2010). The online platform facilitates the dissemination and translation of stories-including into languages with few or no previously available print materials. While Internet access still remains a challenge in many African communities, mobile phones are ubiquitous, so stories can be downloaded (when the Internet or an intranet is accessible) or copied onto a phone through a cable. Saide has also developed an app called The African Storybook Reader, which enables users to read stories offline. Furthermore, well-resourced individuals and organizations can access and print these stories for teachers, students, and others who lack Internet access (StrangerJohannessen, 2017b).

The value and need for such easily available and distributable OER is increasingly being recognized internationally (Tuomi, 2013), and in the Canadian educational system there are a number of OER initiatives - notably in the Western provinces (Hare et al., 2017; McGreal, Anderson, \& Conrad, 2016). But much of the focus is on higher education (with Athabasca University as a frontrunner), with joint initiatives like OER Universitas and BCcampus playing important roles in supporting the development of open curricula, textbooks, and Massive Open Online Courses (MOOCs) (McGreal, Anderson, \& Conrad, 2016).

In terms of primary education, however, there are far fewer initiatives that leverage OER for teaching and learning purposes. OER Commons is an international database of resources for teachers that contains some primary materials, mainly in English. Scribjab (scribjab.com) is a Canadian website, developed by Kelleen Toohey and Diane Dagenais at Simon Fraser University, that allows children to create their own bilingual books by writing, drawing, and recording audio, as well as read stories that other children have made. 
First Voices (firstvoices.com) provides language resources in 36 Indigenous languages, while Little Cree Books (littlecreebooks.com) offers what appear to be the only openly licensed children's stories in Canadian Indigenous languages online-featuring a small collection of stories in Cree and English. The stories from Little Cree Books are the first in the collection of Indigenous Storybooks Canada (indigenousstorybooks.ca), which the Storybooks Canada team, under the leadership of Sara Florence Davidson (a Haida First Nations educator), is currently developing. Although all broadly deal with "digital storytelling" and the promotion of home language literacy, each project has a different focus and different strengths. For instance, OER Commons has a wide variety of resources in English, but seems to contain few materials either for English language learners or in non-English languages; Scribjab focuses on the process of creating the stories in a classroom (and showcasing the results of that work), rather than providing standalone reading materials; and Little Cree Books is focused on providing specific information to support community settlement in Edmonton.

Apart from these online resources, several research projects have used students' home languages to support multilingual education through the use of dual language books or student-created, dual-language materials, with great benefits to students (Cummins \& Early, 2011; Naqvi, McKeough, Thorne, \& Pfitscher, 2013; Naqvi, Thorne, Pfitscher, Nordstokke, \& McKeough, 2013; Stille \& Cummins, 2013). In this digital age, however, having such resources online and openly accessible allows for adaptation, flexibility, and the possibility of reaching virtually all the students in the country. The African Storybook, Global ASP, and Storybooks Canada provide a wide range of digital, open access children's stories of varying lengths, levels, and complexity, specifically to promote and encourage reading.

\section{Storybooks Canada}

Storybooks Canada is an ongoing research project, based at the University of British Columbia (UBC), which seeks to promote multilingual literacy for Canada's diverse student population-focusing in particular on the needs of heritage language speaking, immigrant, and refugee children. Central to the project is the Storybooks Canada website (storybookscanada.ca), which leverages openly licensed digital stories from the $\mathrm{ASb}$ and translates them into the most commonly spoken home languages in Canada. We identified 40 of these stories that represent a range of topics and levels of difficulty and would be suitable for a diverse group of Canadian students. All the stories are narratives that reflect the kinds of stories available on the ASb website. We had these stories translated into Amharic, Arabic, Bengali, Cantonese, French, German, Italian, Korean, Mandarin, Oromo, Persian, Polish, Portuguese, Punjabi, Somali, Spanish, Swahili, Tagalog, Turkish, and Urdu. Stories are available in bilingual versions, in both print and audio formats, on a mobile-friendly platform.

The connection between the ASb and Storybooks Canada has been forged by the three authors of this article, who have connected with the ASb in diverse ways: Espen Stranger-Johannessen did his $\mathrm{PhD}$ research on the ASb in Uganda; Liam Doherty is primarily responsible for the development of the Global African Storybook Project (Global ASP); and Bonny Norton, a UBC professor with extensive research experience in the African context, serves as the Research Advisor of the ASb and has been working actively 
with the ASb initiative since 2013 (Norton \& Welch, 2015; Stranger-Johannessen, 2015; Welch, Tembe, Wepukhulu, Baker, \& Norton, 2014).

Storybooks Canada deliberately breaks with traditions of global knowledge flows, which have often tended to run from the “Global North” to the "Global South”. By bringing African stories to Canadian classrooms, and by drawing on the digital expertise of an African organization, we demonstrate that greater democratization of international knowledge flows is both possible and desirable. At one level, this sharing begins with the stories themselves, in that Canadian students are given opportunities to read authentic and captivating stories from a continent too often associated with challenges rather than solutions. At another level, ASb promotes a culture of openness, sharing, and generosity with respect to the use of educational resources. As illustrated below, both the ASb and Storybooks Canada share a vision for greater equity in the context of very diverse linguistic landscapes.

While the African Storybook has provided invaluable open access content for Storybooks Canada, the Storybooks Canada project has, in turn, contributed two important innovations to the larger project of promoting multilingual literacy for the world's diverse children. First, Storybooks Canada targets the needs of a specific country. As such, it customizes digital stories to the educational needs, policies, and curricular goals of a particular nation. Michelle Gilman, who has joined the Storybooks Canada team, is currently linking Storybooks Canada to the new BC Curriculum, which will be posted to the Storybooks Canada website. Second, Storybooks Canada features an audio component not available in the African Storybook. In order for children to develop phonemic awareness-which is associated with and facilitates the development of reading skills for children learning to read alphabetic script - it is very helpful for children to both read and listen to a story. Audio has been recorded for all of the stories and languages on the Storybooks Canada site. This is relevant not only in the classroom, but also in the home, where parents may not be literate in either the home language or the official school language. The availability of audio stories is also very helpful for children or caregivers who may be visually impaired. User-friendly access to stories in audio and print formats on mobile devices facilitates self-directed learning, in which children, with adult oversight, can pace themselves and customize their learning, both at school and at home. This promotes independent learning, an important $21^{\text {st }}$ century skill.

\section{African Stories in Canadian Classrooms}

As described above, the 40 stories that constitute the Storybooks Canada collection all stem from the ASb, which has extensive experience in using these stories in schools, libraries, and other educational institutions in Africa (Welch \& Glennie, 2016a, 2016b). Apart from their use in an African context (as in the example of Uganda, described above), the ASb stories have also been used in Canada, where translators and students at the University of British Columbia have worked together to translate the stories into dozens of non-African languages through Global ASP, a precursor to Storybooks Canada. Additionally, these stories have been used in translation classes at the University of British Columbia, where for the past four years students have gained a deeper understanding of translation theory and African history, culture, and social issues by translating stories such as A Tiny Seed: The Story of Wangari Maathai (see Figure 2) and Crocodile in My Body 
(which deals with HIV in sub-Saharan Africa; see Figure 3) into Japanese as well as intersemiotic live and video performances (see Figure 4).

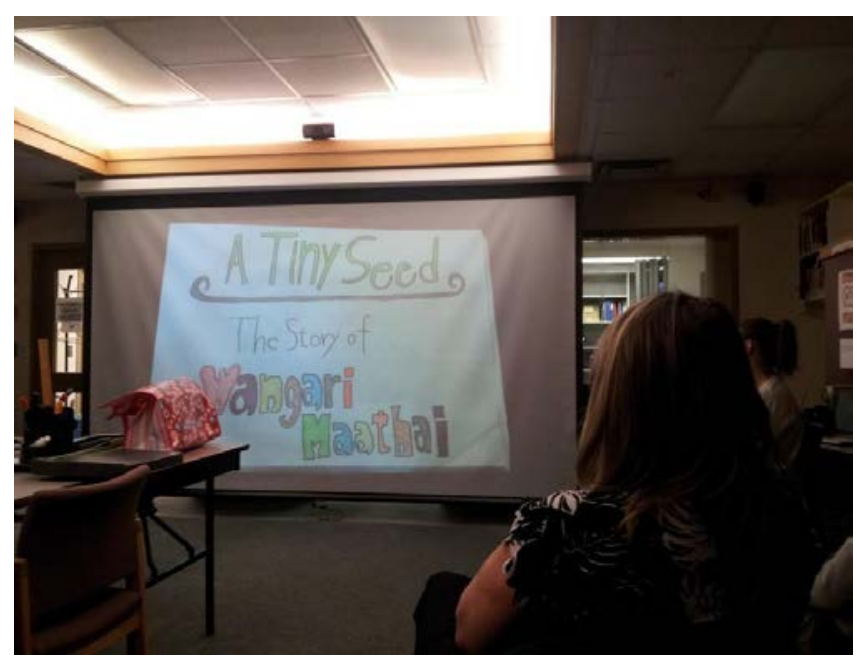

Figure 2: Film adaptation of “A Tiny Seed: The Story of Wangari Maathai” (2015). 


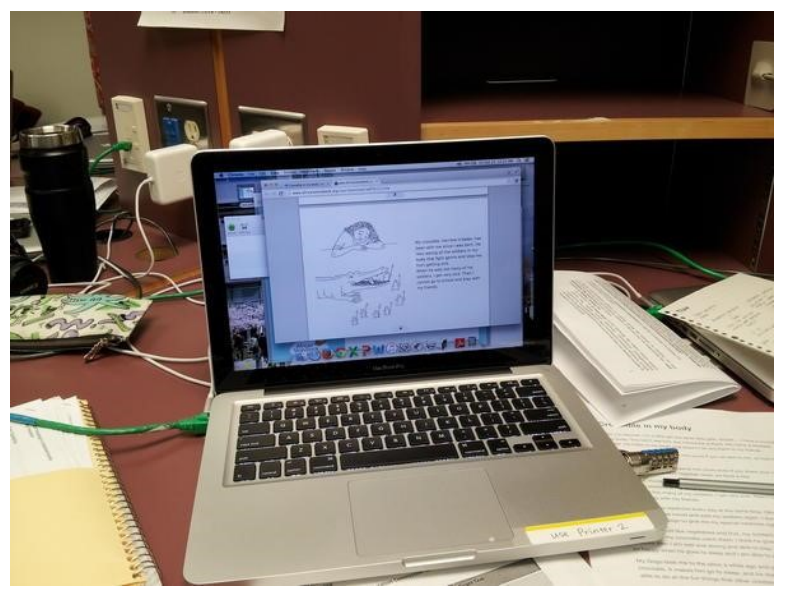

Figure 3. A student working on translating the African Storybook story "A Crocodile in My Body” into Japanese (2015).

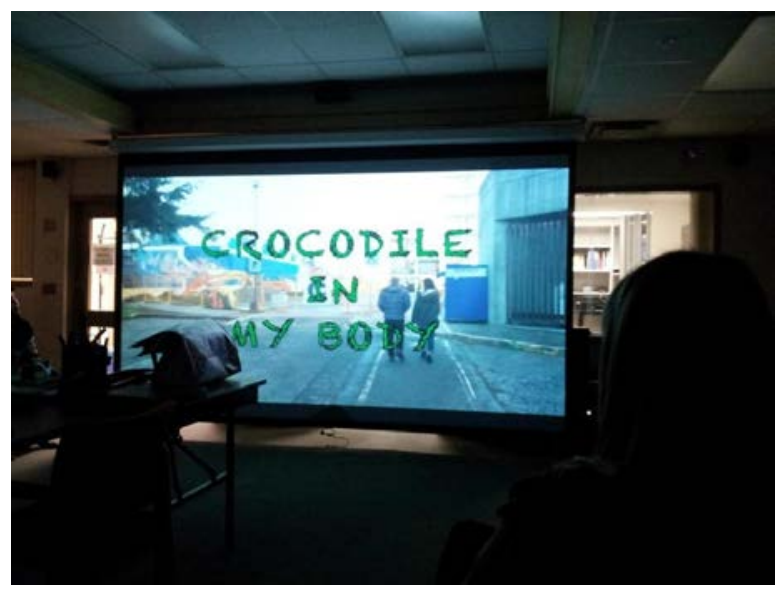

Figure 4: Video adaptation of "Crocodile in My Body," a South African story about the prevalence of HIV in sub-Saharan Africa (2015).

Canadian teachers have also been introduced to the stories as tools for teaching foreign languages. For example, at a 2016 workshop for teachers of Chinese as a Foreign Language held in Vancouver, teachers learned how a combination of bilingual, monolingual, wordless, and pictureless stories could be used for a variety of communicative classroom activities. Some examples of these activities include working in groups to create a new story based on pictures in a wordless storybook; creating images to illustrate the story in a pictureless storybook; looking for patterns in a bilingual story to increase language awareness (either with a language that students are not familiar with or with their first language); and back-translating monolingual versions of the stories and comparing them with existing translations. 


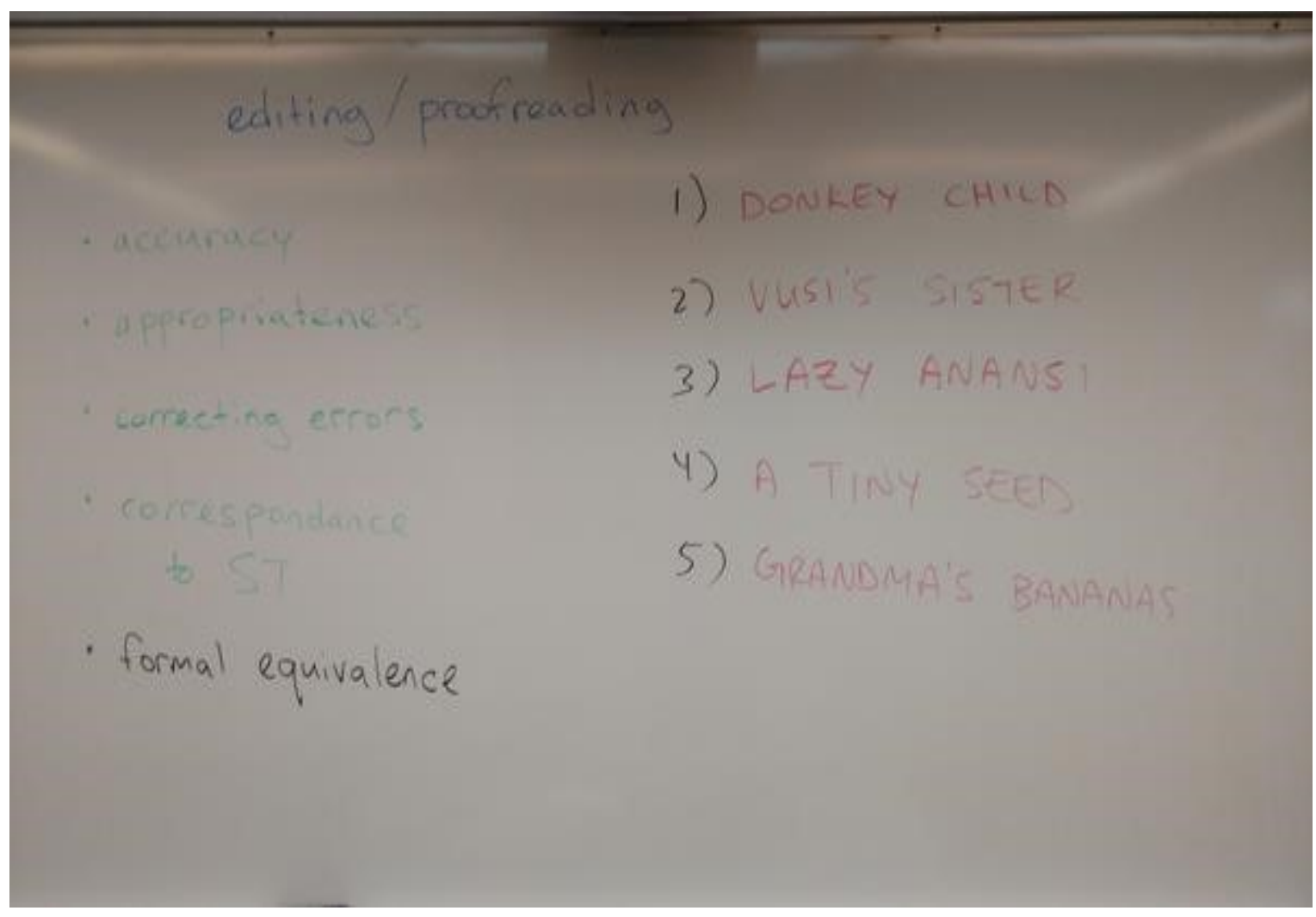

Figure 5: African Storybook stories in a Canadian classroom (2016).

Storybooks Canada builds on these experiences and the demonstrated potential for rich classroom activities with ASb stories. The Storybooks Canada website has been specifically designed to address the needs of primary school teachers working on both computers and mobile devices. The user interface is simple and centres on the stories themselves, which are represented by large front and cover pictures, and labelled according to difficulty level. Each of the 40 stories is available in all 10 languages of the project, with audio recordings of each story available page by page. This means that it is possible to read the stories bilingually, and listen to the audio recording at the same time. Thus, even users who are able to speak but not read their heritage language can use the website and benefit from the cognitive advantages of engaging with content in their home language (Oakes et al., 2015). This is important both for English language learners with limited command of English (in which case teachers may sometimes struggle to convey the meaning of an English text), and heritage language learners who speak English natively (for whom teachers may be unable to find or dedicate resources to develop their multilingual abilities).

In order to further support teachers in using these stories, the Storybooks Canada website includes suggestions on how to use these stories in the classroom. Children's stories in general are a rich resource for activities, such as predicting story development, building vocabulary, and viewing a situation from multiple vantage points. Individual students may choose to read a bilingual version, while other students who are fully proficient in English can read the English version. In addition, teachers are encouraged to: 
- use one or two books in the classroom and then point students to the rest of the books online for free, voluntary reading (Krashen, 2011)

- assign groups to re-enact each page of the story and then perform them in order

- stage re-enactments of the stories, taking photos instead of performing them

- highlight or underline words or phrases that students may not understand, and use the bilingual versions to clarify the meaning of that word or phrase

As the project develops and we receive more feedback on teachers' use of and experiences with these stories in the classroom, the website will be updated with further ideas and shared experiences of using these stories for equitable, multilingual education.

\section{Conclusion}

In this paper we have argued that equity in digital literacy is associated with both access to resources as well as opportunities to engage with digital resources in the home or first language. In the African context, where digital technology and Internet connectivity is growing rapidly, attention to multilingualism is of paramount importance to ensure equitable access to information and literacy development. The ASb has made an important contribution to addressing digital inequity in the African context. However, the potential of this initiative will only be fully realized when there is greater access to digital and print services and resources.

In Canada, equity in digital literacy is facing different challenges. We have focused on students with non-official home languages — the target group of Storybooks Canadaincluding heritage speakers as well as immigrants and refugees. In the next stage of this project, we will increase the number of languages and further develop resources for teachers and parents that outline ways to use these stories. While Michelle Gilman and Bonny Norton are conducting research on the potential of using the stories with young readers in Vancouver, Asma Afreen, another team member, is researching the challenges of translating stories from English into Bengali. We plan to pilot this project in classrooms to demonstrate how these stories can facilitate literacy and language learning, identify connections between the stories and the new BC Curriculum, and learn how we might better tailor the website and other resources for teachers and other stakeholders. We are also excited by the potential of our sister project, Indigenous Storybooks Canada (indigenousstorybooks.ca), which seeks to make Indigenous stories available in a variety of Indigenous languages as well as English, French, and other languages common in Canada.

Storybooks Canada has benefited greatly from the stories, experiences, and generosity of the ASb, and is reciprocating this flow of knowledge by sharing experiences, technical solutions, and new translations of stories into Arabic, French, Portuguese, and other African languages. The two teams are in close contact, and the ASb Research Advisor, Bonny Norton, is directly involved in both projects-further ensuring continued collaboration and knowledge sharing. In the process of working with a large number of languages, including recording audio and non-Latin scripts, we have learned a great deal about the possibilities and challenges of working with multilingual educational resourcesincluding, for instance, paying close attention to right-to-left orthographies and conventions for punctuation and other literacy practices that vary between and within 
languages and language communities. While a story in a different language and script might appear daunting, our advice to teachers and parents is to keep in mind that every story conveys the same message, page by page, regardless of the language it is written inand that they can always quickly switch to either English or French to check for meaning using the convenient language buttons at the side of each page.

This project represents a new area of research, with promising team building possibilities for teachers, parents, and policymakers in Canada. It also provides much needed resources for migrants and new refugees. More broadly, it encourages gradual change in the direction of global communication flows (e.g., shifting from North-South to South-North) while supporting both English/French literacy and mother tongue maintenance across Canadian communities. Together, the African Storybook and Storybooks Canada contribute to promoting equity in digital literacy in their respective communities, and offer a promising vision for social and educational change in the $21^{\text {st }}$ century.

\section{References}

Babaci-Wilhite, Z. (2010). Why is the choice of the language of instruction in which students learn best seldom made in Tanzania? In Z. Desai, M. A. S. Qorro, \& B. Brock-Utne (Eds.), Educational challenges in multilingual societies: LOITASA Phase Two Research (pp. 281-305). Cape Town, South Africa: African Minds.

Baker, C. (2011). Foundations of bilingual education and bilingualism (5th ed.). Bristol, UK: Multilingual Matters.

Creese, A., \& Blackledge, A. (2010). Translanguaging in the bilingual classroom: A pedagogy for learning and teaching? The Modern Language Journal, 94(1), 103115. doi:10.1111/j.1540-4781.2009.00986.x

Cummins, J. (2000). Language, power, and pedagogy: Bilingual children in the crossfire. Clevedon, UK: Multilingual Matters.

Cummins, J. (2011). Literacy engagement. The Reading Teacher, 65(2), 142-146. doi:10.1002/TRTR.01022

Cummins, J., \& Early, M. (2011). Identity texts: The collaborative creation of power in multilingual schools. Stoke-on-Trent, UK: Trentham Books.

Cummins, J., Mirza, R., \& Stille, S. (2012). English language learners in Canadian schools: Emerging directions for school-based policies. TESL Canada Journal, 29(SI6), 25-48.

García, O., \& Kleifgen, J. A. (2010). Educating emergent bilinguals: Policies, programs, and practices for English language learners. New York, NY: Teachers College Press.

Gunderson, L., D'Silva, R. A., \& Odo, D. M. (2014). ESL (ELL) literacy instruction: A guidebook to theory and practice. New York, NY: Routledge.

Hare, J., Darvin, R., Doherty, L., Early, M., Filipenko, M., Norton, B., Soni, D., \& Stranger- Johannessen, E. (2017). Digital storytelling and reconciliation. In P. Tortell, P., M. Young, \& P. Nemetz (Eds.), Reflections of Canada: Illuminating our opportunities and challenges at 150+ years (pp. 200-205). Vancouver, BC: UBC Peter Wall Institute for Advanced Studies

Krashen, S. D. (2011). Free voluntary reading. Santa Barbara, CA: Libraries Unlimited. 
Laguarda, A. I., \& Woodward, W. P. (2013). They own this: Mother tongue instruction for indigenous Kuku Children in Southern Sudan. School Psychology International, 34(4), 453-469.

Lareau, A. (2011). Unequal childhoods: Class, race, and family life. Berkeley, CA: University of California Press.

McGreal, R., Anderson, T., \& Conrad, D. (2016). Open educational resources in Canada. In F. Miao, S. Mishra, \& R. McGreal (Eds.), Open educational resources: Policy, costs, and transformation (pp. 63-76). Paris, France: UNESCO.

Naqvi, R., McKeough, A., Thorne, K., \& Pfitscher, C. (2013). Dual-language books as an emergent-literacy resource: Culturally and linguistically responsive teaching and learning. Journal of Early Childhood Literacy, 13(4), 501-528.

Naqvi, R., Thorne, K. J., Pfitscher, C. M., Nordstokke, D. W., \& McKeough, A. (2013). Reading dual language books: Improving early literacy skills in linguistically diverse classrooms. Journal of Early Childhood Research, 11(1), 3-15.

Norton, B., \& Welch, T. (2015). Digital stories could hold the key to multilingual literacy for African children. Retrieved from theconversation.com/digital-stories-couldhold-the-key-to-multilingual-literacy-for-african-children-40405

Oakes, J., Lipton, M., Anderson, L., \& Stillman, J. (2015). Teaching to change the world. London, UK: Routledge.

Ouane, A., \& Glanz, C. (2010). Why and how Africa should invest in African languages and multilingual education: An evidence- and practice-based policy advocacy brief. Hamburg, Germany: UNESCO Institute for Lifelong Education.

Peterson, S. S., \& Heywood, D. (2007). Contributions of families' linguistic, social, and cultural capital to minority-language children's literacy: Parents', teachers', and principals’ perspectives. Canadian Modern Language Review, 63(4), 517-538.

Piper, B., Zuilkowski, S. S., \& Ong'ele, S. (2016). Implementing mother tongue instruction in the real world: Results from a medium-scale randomized controlled trial in Kenya. Comparative Education Review, 60(4), 776-807. doi:10.1086/688493

Statistics Canada. (2012). Linguistic characteristics of Canadians [Language Report]: 2011 Census of population. Retrieved from www12.statcan.gc.ca/censusrecensement/2011/as-sa/98-314-x/98-314-x2011001-eng.cfm

Stille, S., \& Cummins, J. (2013). Foundation for learning: Engaging plurilingual students' linguistic repertoires in the elementary classroom. TESOL Quarterly, 47(3), 630638. doi:10.1002/tesq.116

Stranger-Johannessen, E. (2015). African stories to get and keep kids reading during school holidays. Retrieved from theconversation.com/african-stories-to-get-andkeep-kids-reading-during-school-holidays-51589

Stranger-Johannessen, E. (2017a). Digital stories and the African Storybook: Teaching English in the digital age. In M. Carrier, R. M. Damerow, \& K. M. Bailey (Eds.), Digital language learning and teaching: Research, theory, and practice (pp. 116126). New York, NY: Routledge.

Stranger-Johannessen, E. (2017b). The African Storybook, teachers' resources, and pedagogical practices. International Journal of Educational Development, 52, 2636. doi:10.1016/j.ijedudev.2016.10.003 
Stranger-Johannessen, E., \& Norton, B. (2017). The African Storybook and language teacher identity in digital times. The Modern Language Journal, 101(S1), 45-60. doi:10.1111/modl.12374

Taylor, L. K., Bernhard, J. K., Garg, S., \& Cummins, J. (2008). Affirming plural belonging: Building on students' family-based cultural and linguistic capital through multiliteracies pedagogy. Journal of Early Childhood Literacy, 8(3), 269294.

Trudell, B. (2013). Early grade literacy in African schools: Lessons learned. In H. McIlwraith (Ed.), Multilingual education in Africa: Lessons from the Juba language-in-education conference (pp. 155-161). London, UK: British Council. Retrieved from www.teachingenglish.org.uk/article/multilingual-education-africalessons-juba-language-education-conference

Tuomi, I. (2013). Open educational resources and the transformation of education. European Journal of Education, 48(1), 58-78. doi:10.1111/ejed.12019

Warschauer, M. (2003). Technology and social inclusion: Rethinking the digital divide. Cambridge, MA: MIT Press.

Warschauer, M. (2012). Language and the digital divide. In C. A. Chapelle (Ed.), The Encyclopedia of Applied Linguistics. Hoboken, NJ: Blackwell Publishing. doi:10.1002/9781405198431.wbeal0602

Warschauer, M., \& Matuchniak, T. (2010). New technology and digital worlds: Analyzing evidence of equity in access, use, and outcomes. Review of Research in Education, 34(1), 179-225. doi:10.3102/0091732X09349791

Welch, T., \& Glennie, J. (2016a). OER contributing to early literacy in Africa: Evidence from Saide's African Storybook. In Pan-Commonwealth Forum 8. Commonwealth of Learning (COL) and Open University Malaysia (OUM). Retrieved from dspace.col.org/handle/11599/2534

Welch, T., \& Glennie, J. (2016b). Open educational resources for early literacy in Africa: The role of the African Storybook Initiative. In F. Miao, S. Mishra, \& R. McGreal (Eds.), Open educational resources: Policy, costs and transformation. Paris, France: UNESCO.

Welch, T., Tembe, J., Wepukhulu, D., Baker, J., \& Norton, B. (2014). The African Storybook Project: An interim report. In H. McIlwraith (Ed.), The Cape Town Language and Development Conference: Looking beyond 2015 (pp. 92-95). London, UK: British Council. 